$$
\begin{aligned}
& \text { تشريح و ريختشناسى زيرطايفه آكريمونينه از تيره كلسرخيان در ايران } \\
& \text { مرضيه بيكم فقير، زهرا قندهارى زاده و كلنوش شمشيرى }
\end{aligned}
$$

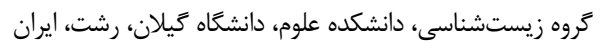

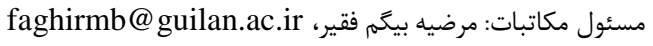

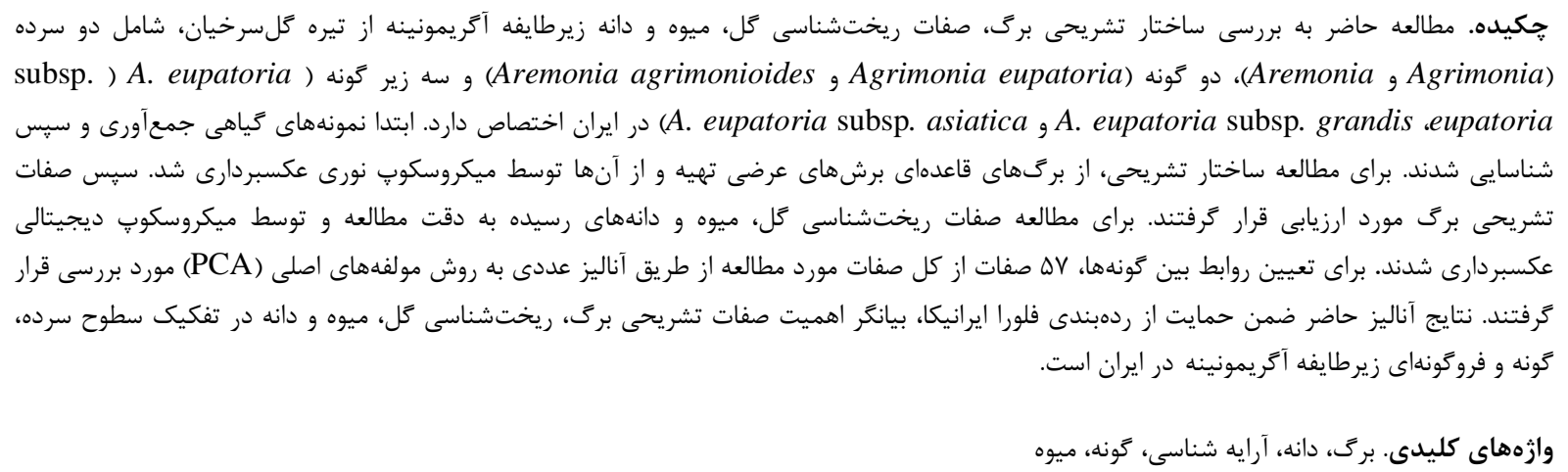

\title{
Comparative anatomical and morphological investigations of the subtribe Agrimoniinae (Rosaceae) in Iran
}

\author{
Marzieh Beygom Faghir, Zahra Ghandharizadeh \& Golnoush Shamshiri \\ Department of Biology, Faculty of Science, University of Guilan, Rasht, Iran \\ Correspondent author: Marzieh Beygom Faghir, faghirmb@guilan.ac.ir
}

\begin{abstract}
The present study was aimed to investigate foliar anatomy and flower, fruit and seed morphology of three subspecies of Agrimonia eupatoria (i.e. A. eupatoria subsp. eupatoria, A. eupatoria subsp. grandis and A. eupatoria subsp. asiatica) and the species of Aremonia agrimonioides, belonging to the subtribe Agrimoniiae (Rosaceae) in Iran. Firstly, plant specimens were collected and then identified on the basis of relevant references. For anatomical analysis, the cross sections of basal leaves of each taxon were prepared, studied by light microscopy and then photographed by means of a digital camera. For morphological analysis, the flower, achene and seed characters were carefully examined using digital microscopy. To determine the relationships among the taxa, 57 characters were included in the Principal Component Analysis (PCA). The results supported the classification proposed by Flora Iranica and showed the importance of leaf anatomical, flower, achene and seed morphological characters in separating inter-generic, intraspecific and interspecific relationships among the representatives of subtribe Agrimoniinea in Iran.
\end{abstract}

Keywords. achene, leaf, seed, species, taxonomy

Received 15.02.2018/Revised 08.11.2018/Accepted 01.01.2020/Published 01.07.2020 دريافت: 
(et al., 2011 جند شكلى در جمعيتهاى

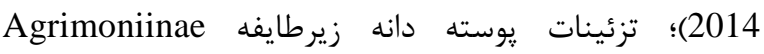
(Chung et al., 2012) (Faghir et al., 2017) Agrimonieae تحقيق براى اولينبار ساختار تشريحى برى گياهان زيرطايفه Agrimoniinae

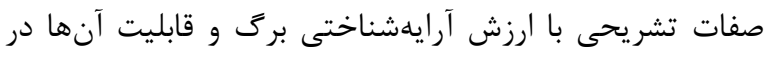

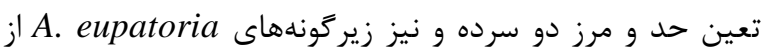

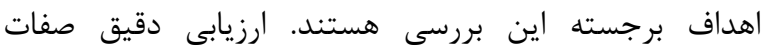

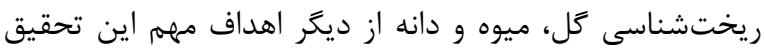

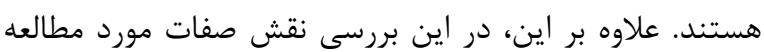

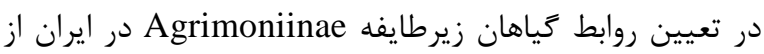
طريق آناليز مولفههاى اصلى (PCA) مورد ارزيابى قرار كرفت.

\section{مواد و روش ها - مان}

براى انجام اين تحقيق ابتدا نمونههاى گياهى (بوجار

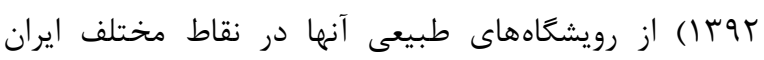

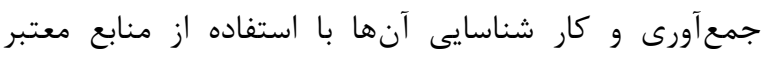
Juzepczuk, 1941; Schönbeck-Temesy, 1969; ) (Khatamsaz, 1993 انجام شد. اين نمونهها در هرباريوم

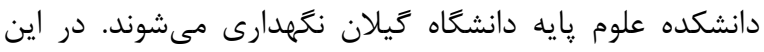
تحقيق از نمونههاى خشكشده هم استفاده شد. اين نمونهها از ازئ دان

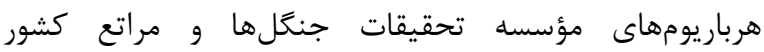

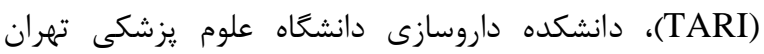
و هرباريوم مركزى دانشخاه تهران (THE)

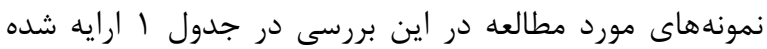

\section{مطالعات ساختار تشريحى}

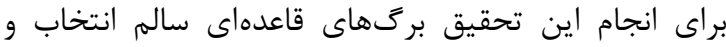

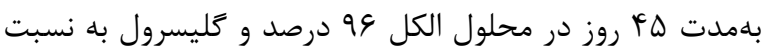

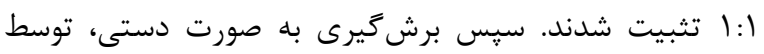

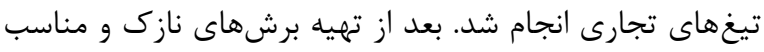

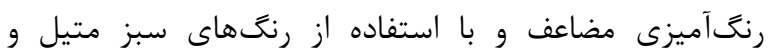

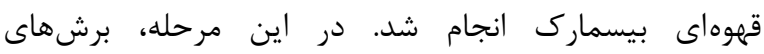
رنغَآميزى شده توسط ميكروسكوب نورى

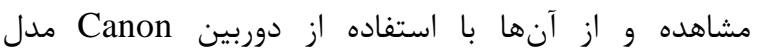

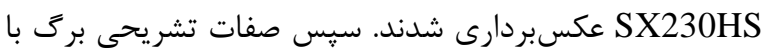
استفاده از نرمافزار Microstructure Measurement نسخد

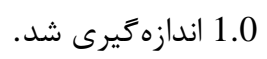

مقلمه

زيرطايفه Agrimoniiae شامل كياهان گلبركدار طايفه Agrimonineae Aphanes L. Alchemilla L. تمراه با سردهنهاى و تحت طايفه Schulze-Menz, 1964; Takhtajan,) Sanguisorbeae Hutchinson, ) Poterieae و و (1997; Kalkman, 2004 1964) ردمبندى مىشدند. زيرطايفه Agrimoniinae

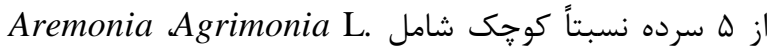
Hagenia Spenceria Trimen ،Necker ex Nestler Leucosidea Eckl. \& Zeyh, J.F.Gmel. Schulze-Menz, 1964; Potter et al., 2007; Zhang et ) (al., 2017 در اين بين، Agrimonia در مناطق معتدله

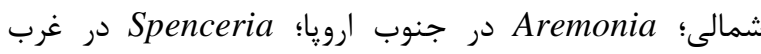
جين؛ Hagenia در مناطق نيمه كوهستانى شرق آفريقا Leucosidea و درب جنوب، شرقى آفريقا و زيمبابوه انتشار دارد (Kerr, 2004). از ميان سردهاى داى نام برده شده، Agrimonia Agrimonia eupatoria L. داراى سه كونه شامل A. repens L. A. aitchisonii Schönbeck-Temesy. و سه زيركونه شامل A. eupatoria subsp. eupatoria L. A. , A. eupatoria subsp. asiatica (Juz.) Skalický eupatoria subsp. grandis (Andrz. ex C.A.Mey.) Schönbeck-) در محدوده فلورا ايرانيكا است Bornm.

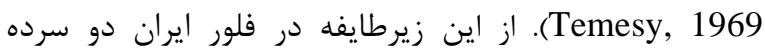
شامل Agrimonia (با يك تونه A. eupatoria)

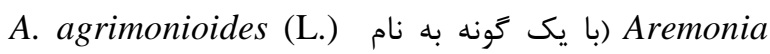

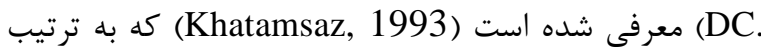

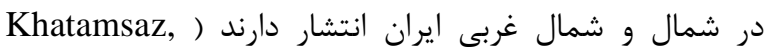
1993; $\quad$ Schönbeck-Temesy, 1969 A. در برخى از منابع به صورت زيركونهاى Agrimonia eupatoria حالى كه در ساير منابع مانند فلور ايران از يذيرش زيركّونهانهاى A. eupatoria كياهان زيرطايفه Agrimoniiae يِيوسته موضوع تحقيقات

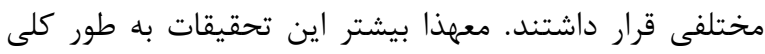

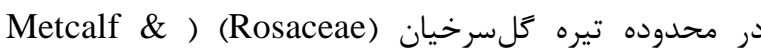
Chalk, 1957; Reitsma, 1966; Hebda et al., 1988; Hebda \& Chinnappa, 1990; Tantawy \& Naseri, (2003; Lee et al., 2011 در مورد كياهان زيرطايفه Agrimoniinae انجام شدهاست،

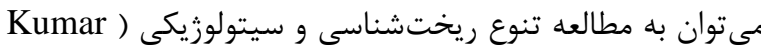


جدول ا- اطلاعات مربوط به كونهاى مورداستفاده در اين تحقيق.

Table 1. Information of the studied species.

\begin{tabular}{|c|c|}
\hline Tribe Agrimonieae & Collection data \\
\hline $\begin{array}{l}\text { I. Subtribe Agrimoniinae } \\
\text { 1. Agrimonia eupatoria } \mathrm{L} \text {. } \\
\text { 1.1 Agrimonia eupatoria subsp. eupatoria }\end{array}$ & $\begin{array}{l}\text { Guilan prov.: Lahijan, Faghir } 5753(\mathrm{GUH}) \\
\text { West Azarbayejan prov.: } 14 \mathrm{~km} \text { to Ashgholor, Arasvali } 55289 \\
\text { (THE) } \\
\text { Mazandaran prov.: South west Chaloos, } 400 \mathrm{~m} \text {, Attar \& Zamani } \\
8595 \text { (TUH) } \\
\text { Tehran prov.: Damavand, } 1900 \mathrm{~m} \text {, Mozafarian } 32384 \text { (TARI) }\end{array}$ \\
\hline $\begin{array}{l}\text { 1.2. A. eupatoria subsp. grandis. (Andrz. ex Ascherson \& } \\
\text { Graebner) Bornm. }\end{array}$ & $\begin{array}{l}\text { Mazandaran prov.: Noshahr, Darzi Kola, Sabeti } 2277 \text { (TARI) } \\
\text { Mazandaran prov.: Kelachai, Ghahreman 26281(THE) }\end{array}$ \\
\hline 1.3 A. eupatoria subsp. asiatica (Juz) Schönbeck - Temesy) & $\begin{array}{l}\text { Mazandaran prov.: Ramsar, } 1962 \text { m, Mobaiien } 401 \text { (THE) } \\
\text { Markazi prov.: Arak, } 1900 \text { m, Julliet } 402 \text { (THE) }\end{array}$ \\
\hline $\begin{array}{l}\text { 2. Aremonia Necker ex Nestle } \\
\text { 2.1 A. agrimonioides (L.) DC. }\end{array}$ & $\begin{array}{l}\text { Gilan prov.: Asalem to Khalkhal road, } 1200 \mathrm{~m} \text {, Faghir } 5754 \\
\text { (GUH) } \\
\text { Mazandaran prov.: Ramsar, Janat Roodbar, } 1150 \mathrm{~m} \text {, Roneh \& } \\
\text { Maassoumi } 21625 \text { (TARI) }\end{array}$ \\
\hline
\end{tabular}

به غير از كونه A. eupatoria subsp. asiatica كه داراى كرى موجدار است. كرى غدهاى به دو صورت سر كرد و و استوانهاى

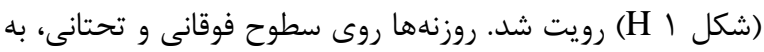

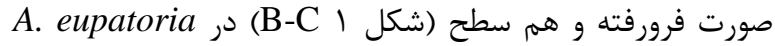
أA subsp. eupatoria A. A. eupatoria subsp. grandis در دو زيركونه (F eupatoria subsp. asiatica

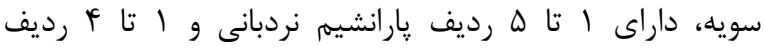

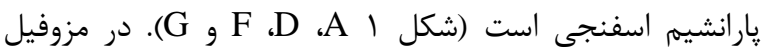

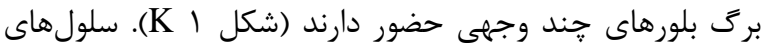

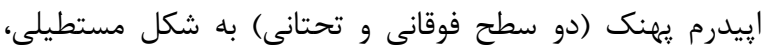
קندضلعى تا مدور هستند و توسط لايه كوتيكول يوشانده

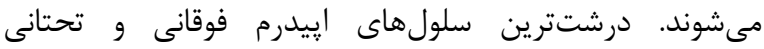

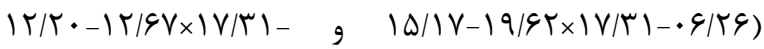
ميكرون) در آن eupatoria subsp. eupatoria

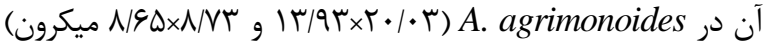

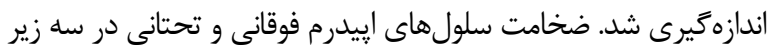

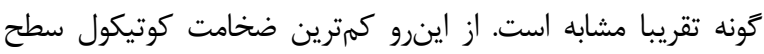

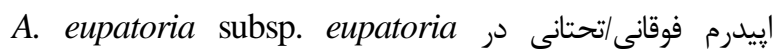

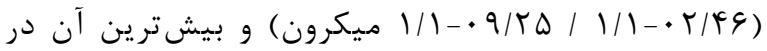
I//-Fa/G. ( I/I-FV/GT) A. eupatoria subsp. asiatica ميكرون) اندازمخيرى شد. بافت مزوفيل در برخى از جمعيتهاى زير

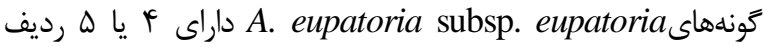
سلولهاى نردبانى (شكل I I I) است. در حالى كه مزوفيل برينك

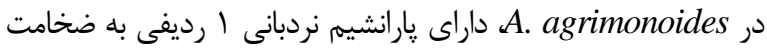

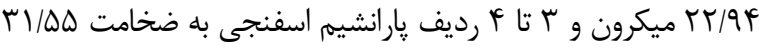

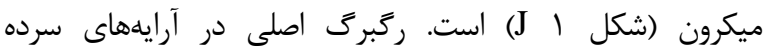

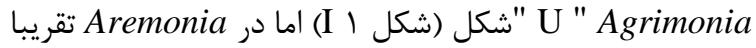

مطالعه ريختشناسى كل، ميوه و دانه

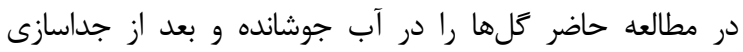
قطعات مختلف از آنها عكسبردارى شد. همجنين ميوه و دانهای

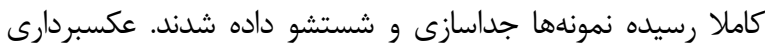

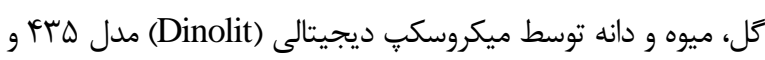

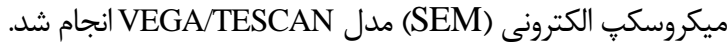
تجزيه دادهها به روش مؤلفه هاى اصلى مانى

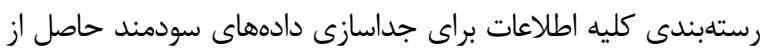

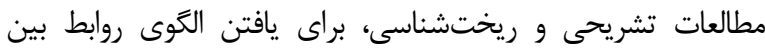

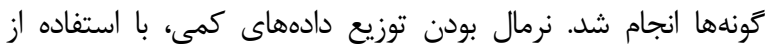

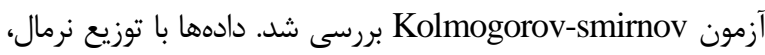

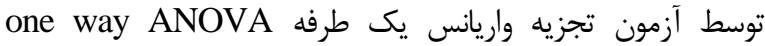

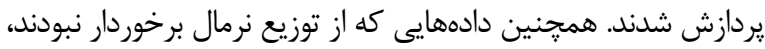

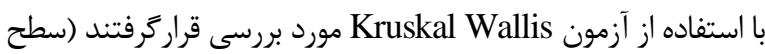

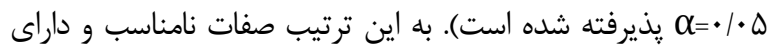

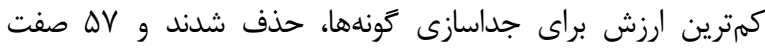
(جدول 9) توسط آناليز مؤلفههاى اصلى ( Principal Component PCA يا Pورد بررسى قرار ترفتند. براى انجام كليه (Analysis آناليزهاى آمارى و يردازش دادهها از نرمافزار MINAB SPSS

نتايج ساختار تشريحى برك زيرطايفه Agrimoniinae

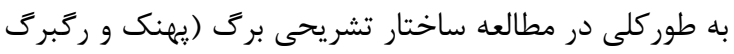

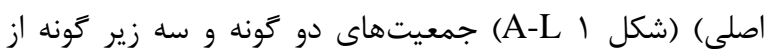

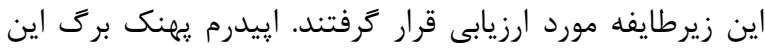

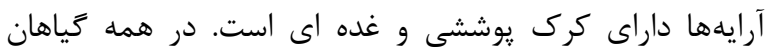
تحت مطالعه، كرك يوششى از نوع راست و افراشته مشاهده شد، 

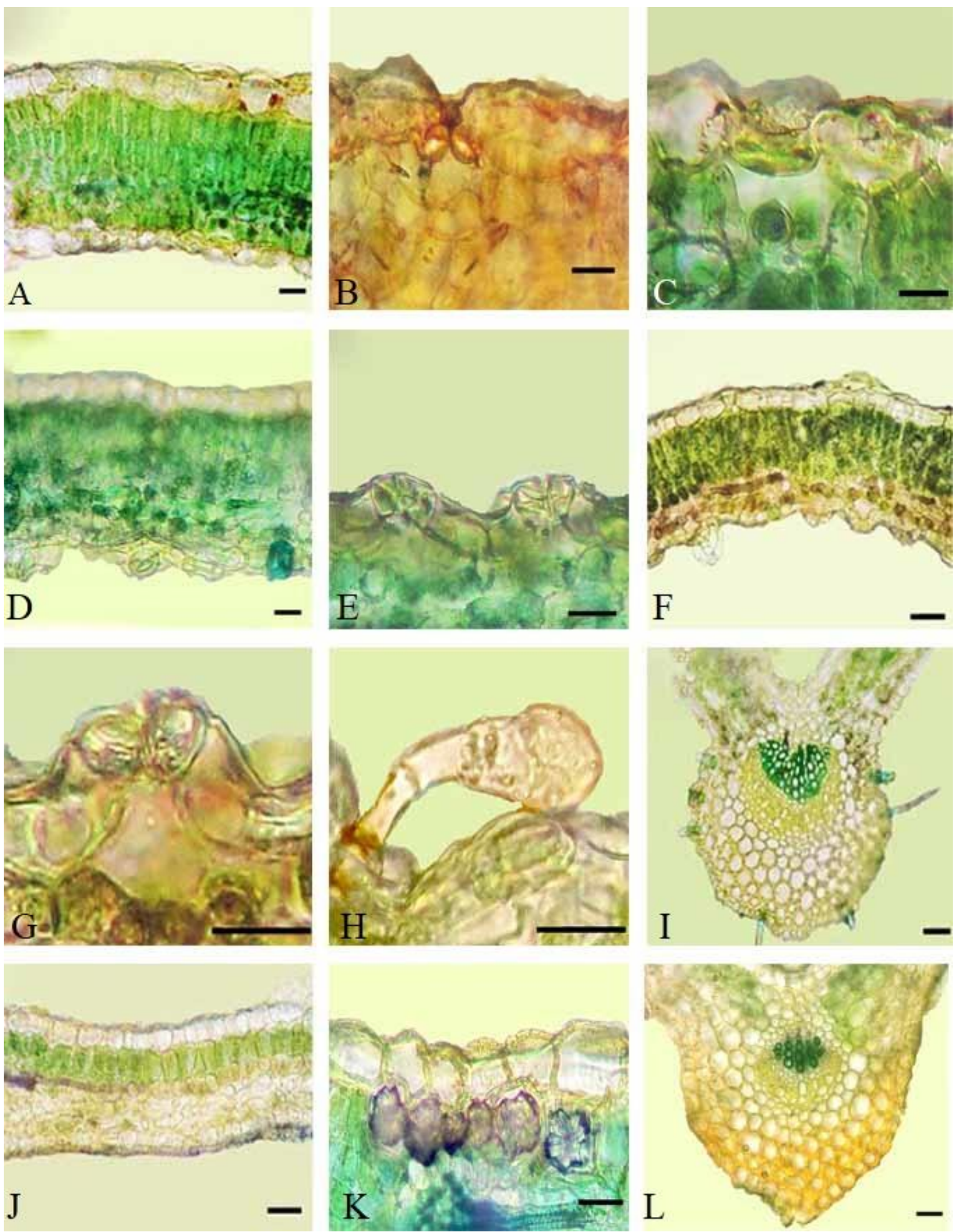

شكل ا- برش عرضى برك شامل بهنك و ركبرى اصلى در زيرطايفه Agrimonia eupatoria subsp. eupatoria .A-C .Agrimoniinae.E Agria .Aremonia agrimonioides .J-L Agrimonia eupatoria subsp asiatiica .F-I .A. eupatoria subsp. grandis.

Fig. 1. Leaf cross-section including blade and midrib in subtribe Agrimoniinae. A-C. Agrimonia eupatoria subsp. eupatoria. D-E. A. eupatoria subsp. grandis.F-I. A. eupatoria subsp. asiatica. J-L. Aremonia agrimonioides. Scale: 4 $\mathrm{mm}$. 
جدول r- صفات تشريحى يهنك درگونههاى مورد استفاده اين تحقيق

Table 2. Leaf anatomical characters in the species studied

\begin{tabular}{|c|c|c|c|c|}
\hline \multirow[t]{2}{*}{ Characters } & \multicolumn{4}{|c|}{ Species } \\
\hline & A. eupatoria subsp. eupatoria & A. eupatoria subsp. grandis & A. eupatoria subsp. asiatica & A. agrimonoides \\
\hline \multirow{2}{*}{ UCT } & $0.62(1.02 \pm 0.48) 1.75$ & $0.77(1.44 \pm 0.42) 1.82$ & $0.6(1.47 \pm 0.56) 1.92$ & $1.22(1.62 \pm 0.37) 1.97$ \\
\hline & $0.82(1.46 \pm 0.44) 1.87$ & $0.66(1.37 \pm 0.32) 1.67$ & $0.60(1.62 \pm 0.59) 2.17$ & $1.37(1.52 \pm 0.26) 1.63$ \\
\hline \multirow[t]{2}{*}{ LCT } & $0.60(1.25 \pm 0.55) 1.92$ & $0.6(1.47 \pm 0.69) 2.17$ & $0.85(1.45 \pm 0.55) 1.92$ & $1.17(1.58 \pm 0.49) 2.12$ \\
\hline & $0.85(1.09 \pm 0.37) 1.7$ & $0.4(1.35 \pm 0.23) 1.93$ & $1.22(1.60 \pm 035) 1.97$ & $1.23(1.18 \pm 0.32) 2.26$ \\
\hline \multirow[t]{2}{*}{ LUE } & $15.4(17.62 \pm 3.31) 23.22$ & $9.52(11.57 \pm 1.47) 3.05$ & $10.1(14.03 \pm 2.75) 16.82$ & $10.47(13.93 \pm 2.28) 16.35$ \\
\hline & $12.72(15.19 \pm 1.43) 16.45$ & $9.36(10.36 \pm 1.25) 12.36$ & $11.25(12.45 \pm 1.26) 14.52$ & $9.26(11.34 \pm 1.21) 15.38$ \\
\hline \multirow{2}{*}{ WUE } & $27.65(31.26 \pm 2.50) 34.37$ & $18.1(19.03 \pm 0.71) 19.87$ & $20(21.30 \pm 1.14) 22.42$ & $18.57(20.03 \pm 0.87) 20.85$ \\
\hline & $16.10(17.06 \pm 1.16) 19$ & $17.29(18.34 \pm 1.89) 18.47$ & $17.77(18.65 \pm 0.61) 19.50$ & $17.33(18.27 \pm 0.63) 19.38$ \\
\hline \multirow[t]{2}{*}{ LuE } & $10.72(12.67 \pm 1.5) 13.92$ & $7.8(10.91 \pm 2.50) 14.52$ & $7.9(9.34 \pm 1.06) 10.37$ & $7.42(8.65 \pm 1.28) 10.70$ \\
\hline & $9.27(12.2 \pm 1.65) 16$ & $8.23(9.29 \pm 2.33) 12.67$ & $7.32(8.66 \pm 1.35) 10.65$ & $7.32(7.87 \pm 1.39) 19.94$ \\
\hline \multirow[t]{2}{*}{ LET } & $23.05(25.63 \pm 1.69) 27.52$ & $17.92(18.79 \pm 0.89) 20.25$ & $17.92(18.95 \pm 0.79) 19.82$ & $8.12(8.73 \pm 0.57) 9.5$ \\
\hline & $16.07(17.31 \pm 0.88) 18.55$ & $16.87(16.77 \pm 0.36) 18.32$ & $12.55(13.31 \pm 0.64) 14$ & $7.36(7.45 \pm 0.89) 8.43$ \\
\hline \multirow[t]{2}{*}{ St } & Depressed & Raised & Raised & Oblate \\
\hline & Raised & Raised & Raised & Oblate \\
\hline \multirow[t]{2}{*}{ PalT } & $84.6(122.92 \pm 4.93) 149.35$ & $32.52(34.64 \pm 1.79) 37.12$ & $28.27(29.97 \pm 1.48) 32.32$ & $20.85(22.94 \pm 1.57) 24.45$ \\
\hline & $24.27(29.43 \pm 5.39) 37.37$ & $28.47(31.39 \pm 1.36) 35.39$ & $24.4(30.29 \pm 3.55) 33.75$ & $22.37(21.36 \pm 1.36) 23.36$ \\
\hline \multirow[t]{2}{*}{ NPal } & $4-5$ & $1-2$ & $1-2$ & 1 \\
\hline & $4-5$ & $1-2$ & $1-2$ & 1 \\
\hline \multirow[t]{2}{*}{ SP } & - & $27.5(29.04 \pm 1.83) 32.02$ & $30.12(31.92 \pm 2.9) 36.37$ & $27.62(31.55 \pm 2.57) 34.12$ \\
\hline & $28.07(37.17 \pm 5.58) 42.75$ & $26.7(27.36 \pm 1.45) 30.27$ & $31.50(34.92 \pm 2.54) 38.12$ & $26.67(33.42 \pm 1.78) 35.47$ \\
\hline \multirow{2}{*}{ NSP } & - & $2-3$ & $2-3$ & $3-4$ \\
\hline & $2-3$ & $2-3$ & $2-3$ & $3-4$ \\
\hline \multirow[t]{2}{*}{$\mathbf{T}$} & - & + & + & + \\
\hline & + & + & + & + \\
\hline \multirow[t]{2}{*}{ G } & - & - & cylindrical - circular head & cylindrical - circular head \\
\hline & $2-3$ & - & cylindrical - circular head & cylindrical - circular head \\
\hline $\mathbf{C}$ & Polygonal & Polygonal - cubic & Polygonal & Polygonal \\
\hline & - & Polygonal - cubic & Polygonal & Polygonal \\
\hline & - & Polygonal - cubic & Polygonal & Polygonal \\
\hline MSh & U shape & U shape & U shape & Triangular \\
\hline LUEE & $20.82(25.36 \pm 3.26) 28.2$ & $12.7(14.30 \pm 0.96) 15$ & $12.85(15.87 \pm 2.26) 19.07$ & $18.8(20.51 \pm 1.55) 22.97$ \\
\hline & $13.52(16.21 \pm 2.04) 18.27$ & $11.1(13.79 \pm 0.37) 16.32$ & $13.17(14.61 \pm 1.31) 16.10$ & $17.3(21.63 \pm 1.28) 21.39$ \\
\hline WUEE & $17.90(19.10 \pm 1.47) 21.65$ & $8.35(9.37 \pm 1.00) 11.05$ & $5.87(8.44 \pm 2.05) 11.12$ & $14.62(15.60 \pm 1.28) 17.05$ \\
\hline & $15.82(18.07 \pm 1.44) 19.5$ & $7.73(8.41 \pm 1.29) 10.65$ & $5.47(6.4 \pm 0.76) 7.22$ & $13.79(14.76 \pm 1.25) 16.39$ \\
\hline LEL & $9.92(11.80 \pm 1.06) 12.55$ & $8.35(9.37 \pm 1.00) 11.05$ & $5.87(8.44 \pm 2.05) 11.12$ & $14.62(15.60 \pm 1.28) 17.05$ \\
\hline & $10.1(11.59 \pm 1.06) 12.65$ & $7.73(8.41 \pm 1.29) 10.65$ & $5.47(6.4 \pm 0.76) 7.22$ & $13.79(14.76 \pm 1.25) 16.39$ \\
\hline LEW & $15.70(16.83 \pm 1.06) 18.20$ & $8.45(9.04 \pm 0.55) 9.9$ & $7.27(7.63 \pm 0.30) 8.12$ & $12.5(13.13 \pm 0.63) 13.87$ \\
\hline & $6.72(7.52 \pm 0.67) 8.47$ & $7.39(8.70 \pm 0.49) 8.93$ & $4.37(5.12 \pm 0.63) 6.02$ & $13.78(12.43 \pm 0.79) 14.97$ \\
\hline UColT & $34.32(35.75 \pm 1.50) 38.2$ & $19.35(20.51 \pm 0.81) 21.62$ & $20(20.91 \pm 0.85) 22.32$ & $27.5(28.18 \pm 0.66) 29.27$ \\
\hline & $15.82(16.44 \pm 1.05) 18.32$ & $17.82(19.39 \pm 0.93) 22.37$ & $15.5(17.18 \pm 1.05) 18.42$ & $24.72(27.37 \pm 0.69) 29.69$ \\
\hline LColT & $40.72(41.47 \pm 0.63) 42.15$ & $35(36.27 \pm 0.8) 36.85$ & $38.12(38.99 \pm 1.21) 41.1$ & $43.07(44.02 \pm 0.87) 45.1$ \\
\hline & $28.75(30.79 \pm 1.29) 31.9$ & $34.38(35.79 \pm 0.65) 37.73$ & $33.07(33.68 \pm 0.56) 34.32$ & $40.82(43.29 \pm 0.91) 43.74$ \\
\hline UPT & $28.75(30.79 \pm 1.29) 31.9$ & $18.8(19.88 \pm 0.86) 21.02$ & $25.15(25.94 \pm 0.75) 27.12$ & $30.30(31.41 \pm 0.77) 32.42$ \\
\hline & $19.62(20.26 \pm 0.55) 20.92$ & $17.6(18.67 \pm 0.36) 22.72$ & $25.67(27.33 \pm 1.34) 28.95$ & $31.28(30.37 \pm 0.46) 30.38$ \\
\hline LPT & $41.12(41.97 \pm 0.87) 43.45$ & $36.27(37.57 \pm 0.83) 38.42$ & $38.55(40.48 \pm 1.35) 41.9$ & $49.95(52.88 \pm 1.79) 54.89$ \\
\hline & $28.05(28.87 \pm 0.61) 29.77$ & $34.73(36.49 \pm 0.79) 39.38$ & $45.97(49.18 \pm 2.2) 51.70$ & $48.87(49.83 \pm 1.63) 52.73$ \\
\hline NUColL & $1-3$ & $1-2$ & $1-4$ & $1-4$ \\
\hline & $1-2$ & $1-2$ & $1-2$ & $1-2$ \\
\hline NLColL & $1-4$ & $1-4$ & $1-3$ & $1-3$ \\
\hline & $1-3$ & $1-4$ & $1-2$ & $1-3$ \\
\hline NUPL & $1-3$ & $1-3$ & $1-2$ & $1-3$ \\
\hline & $1-4$ & $1-3$ & $1-3$ & $1-3$ \\
\hline NLPL & $1-3$ & $1-4$ & $1-3$ & $1-3$ \\
\hline & $1-4$ & $1-4$ & $1-3$ & $1-3$ \\
\hline NXV & 6 & 7 & 11 & 5 \\
\hline & 7 & 7 & 10 & 5 \\
\hline MidW & $210.32(210.55 \pm 0.35) 211.17$ & $173(176.06 \pm 1.91) 177.8$ & $260.02(263.2 \pm 2.77) 266.17$ & $291.05(293.45 \pm 1.54) 294.92$ \\
\hline & $138.95(141.24 \pm 1.45) 142.85$ & $165(171.93 \pm 1.83) 179.27$ & $212.57(214.95 \pm 2.09) 217.32$ & $283.49(291.93 \pm 1.82) 293.432$ \\
\hline MidL & $284.07(286.01 \pm 1.69) 287.85$ & $227.52(229.78 \pm 2.08) 232$ & $277.77(278.35 \pm 0.51) 279$ & $252.9(253.88 \pm 0.80) 254.52$ \\
\hline & $184.40(185.93 \pm 1.37) 187.57$ & $223.73(226.91 \pm 2.26) 227.31$ & $250.67(252.47 \pm 1.55) 254.8$ & $247.39(249.73 \pm 0.86) 251.79$ \\
\hline $\begin{array}{l}\text { Abbreviations } \\
\text { Lower epiderr } \\
\text { layers; SP Sp } \\
\text { cell length; W } \\
\text { Thickness; LC } \\
\text { collenchyma I } \\
\text { parenchyma l }\end{array}$ & $\begin{array}{l}\text { CT Upper cuticle thickness; L } \\
\text { cell length; LET Lower epider } \\
\text { y parenchyma thickness; NSP } \\
\text { E Upper epidermis cell width } \\
\text { I, Lower collenchyma thicknes } \\
\text { ers; NLColL Number of Lo } \\
\text { rs; NXV Number of xylem vein }\end{array}$ & $\begin{array}{l}\text { ower cuticle thickness; LUE } \\
\text { ell width; St Stomata; PalT Pa } \\
\text { ber of spongy parenchyma I } \\
\text { L Upper epidermis cell Leng } \\
\text { PT Upper collenchyma Thick } \\
\text { collenchyma layers; NUPL, }\end{array}$ & $\begin{array}{l}\text { er epidermis cell length; WUE } \\
\text { de parenchyma thickness; NP } \\
\text { ars; T Trichrome; G Gland; } \\
\text { LEW Upper epidermis cell } \\
\text {; LPT Lower collenchyma thi } \\
\text { ber of upper parenchyma }\end{array}$ & $\begin{array}{l}\text { per epidermis cell width; LUE } \\
\text { umber of palisade parenchyma } \\
\text { ystal; LUEE Upper epidermis } \\
\text { h; UColT Upper collenchyma } \\
\text { ess; NUColL Number of upper } \\
\text { ers; NLPL Number of lower }\end{array}$ \\
\hline
\end{tabular}


در سرده Agrimonia ميوه فندقه و درون هييانتيوم خاردار

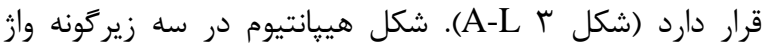

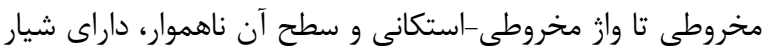

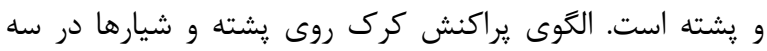

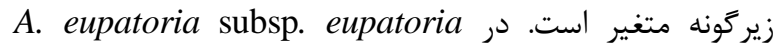

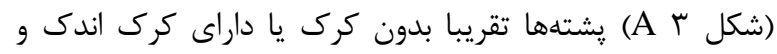

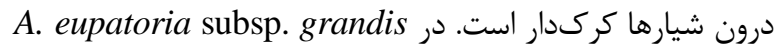

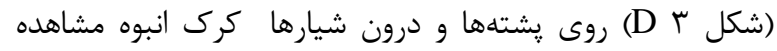

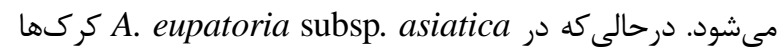

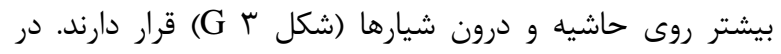

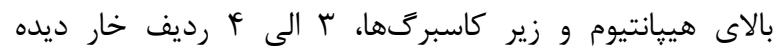

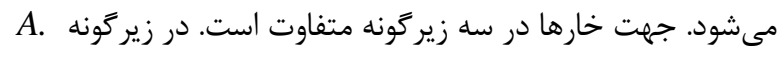
eupatoria subsp. eupatoria

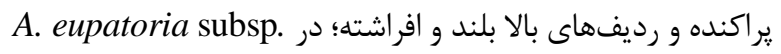
grandis و افراشته و در زيركونه

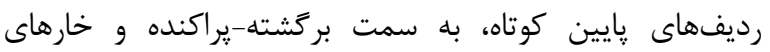

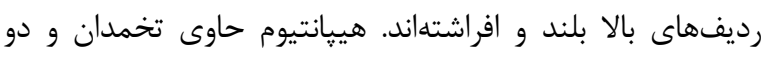

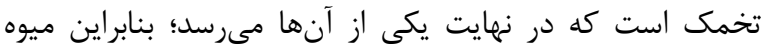
رسيده داراى يك دانه است. ميوه در سرده Aremonia grimonioides بيرون به درون، داخل گريبان قيفىشكل (سبزرنگ، داراى 1 الى

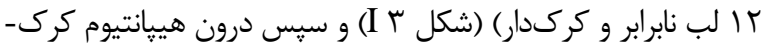

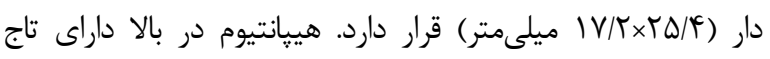

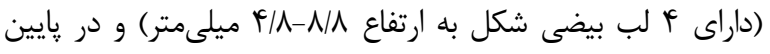

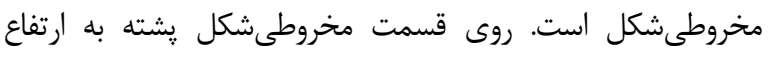

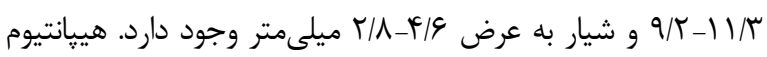

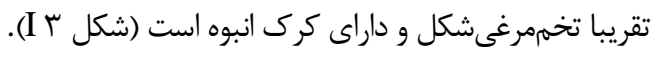
مطالعه ريختشناسى دانه

دانه در A. eupatoria subsp. eupatoria (ش-F r eupatoria subsp. grandis دارال داراى قسمت قاعده اى مسطح و قسمت فوقانى مخروطى-نوكتيز،

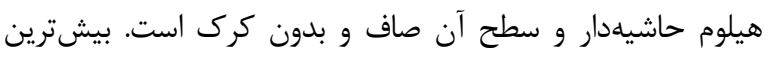
طول و ضخامت هيلوم در A. eupatoria subsp. eupatoria

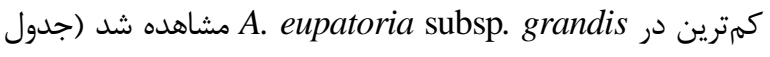
ץ)

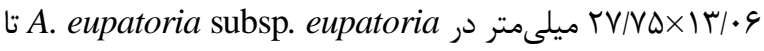

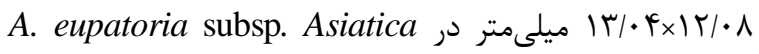

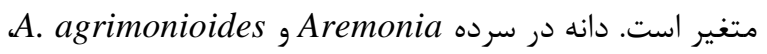

مثلثى (شكل L L)؛ قسمت فوقانى و تحتانى آن داراى ا تا F رديف

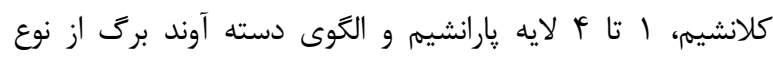

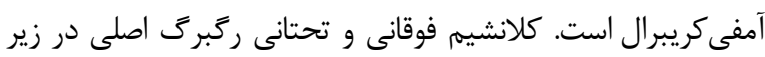

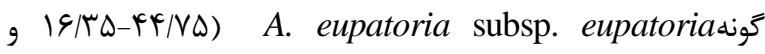

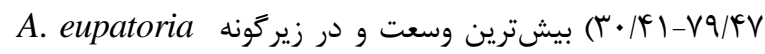
Ssubsp. asiatica

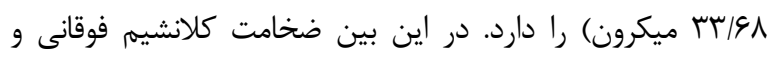

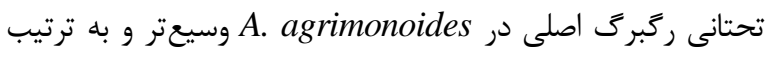

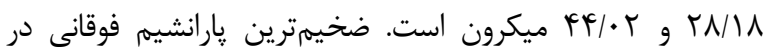
زيركونه A. A eupatoria subsp. epatoria A. agrimonoides ميكرون) و ضخيمترين يارانشيم تحتانى درونه

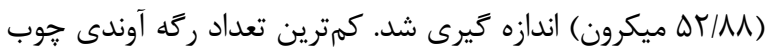

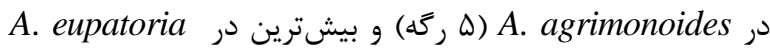
subsp. asiatica مطالعه ريختشناسى كل

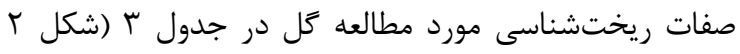

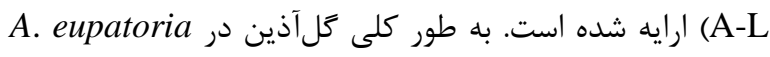

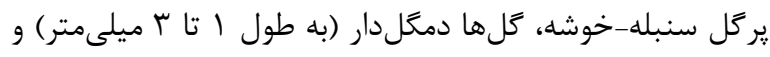

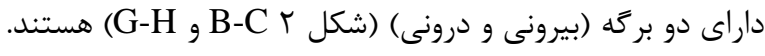

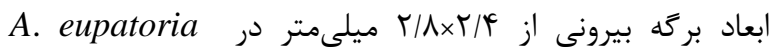
A. eupatoria الى subsp. asiatica subsp. eupatoria

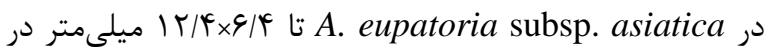
A. eupatoria subsp. grandis

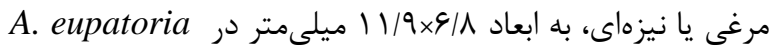
subsp. eupatoria

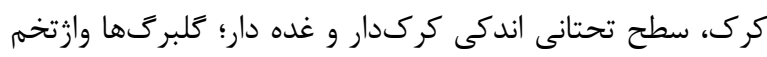

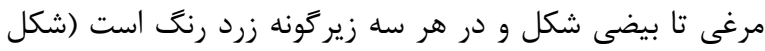

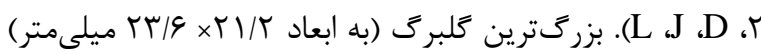

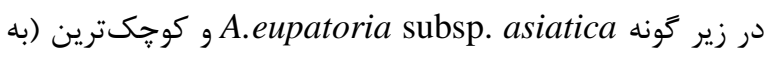

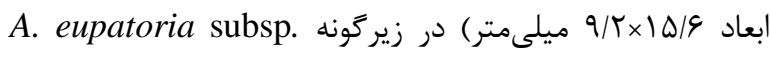

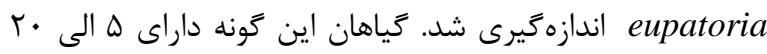

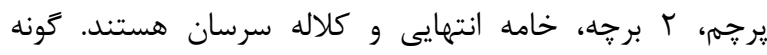
A. agrimonoides

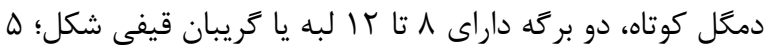

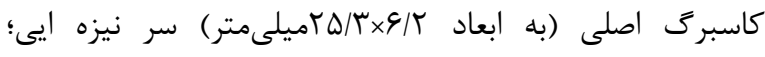

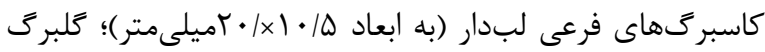
زرد (به ابعاد \&/\&

مطالعه ريختشناسى ميوه 
جدول r- صفات ريختشناسى گل در گونههاى مورد مطالعه تحقيق

Table 3. Flower morphological characters in the species studied

\begin{tabular}{|c|c|c|c|c|c|c|c|c|c|}
\hline Species/Subspecies & $\begin{array}{l}\text { PD } \\
\mathbf{m m}\end{array}$ & NBL & $\begin{array}{l}\mathrm{Ob} \\
\mathrm{mm}\end{array}$ & $\begin{array}{l}\text { Ib } \\
\mathbf{m m}\end{array}$ & CD & $\begin{array}{l}\text { Epi } \\
\text { mm }\end{array}$ & $\begin{array}{l}\text { CS } \\
\text { h }\end{array}$ & PSh & NSt \\
\hline $\begin{array}{l}\text { 1. Agrimonia eupatoria } \\
\text { 1.1. A. eupatoria subsp. eupatoria }\end{array}$ & $9.2 * 15.6$ & 3 & $5.6 * 6.4$ & $7.2 * 8.4$ & $11.9 * 6.8$ & - & $\mathrm{Ob}$ & $\mathrm{Ob}-\mathrm{El}$ & $5-20$ \\
\hline A. eupatoria subsp. grandis & $22.8 * 18.4$ & 3 & $5.1 * 6.4$ & $12.4 * 6.4$ & $11.6 * 6.4$ & - & $\mathrm{E}$ & $\mathrm{Ob}-\mathrm{El}$ & $5-20$ \\
\hline A. eupatoria subsp. asiatica & $23.6 * 21.2$ & 3 & $2.8 * 2.4$ & $3.3 * 4.4$ & $9.6 * 6.9$ & - & $\mathrm{Ob}$ & $\mathrm{Ob}-\mathrm{El}$ & $5-20$ \\
\hline $\begin{array}{l}\text { 2.Aremonia } \\
\text { 2.1 Aremonia agrimonioides }\end{array}$ & $29.6 * 16.4$ & $8-12$ & - & - & $25.3 * 6.2$ & $20 / * 10.5$ & $\mathrm{~L}$ & obco & $5-10$ \\
\hline
\end{tabular}

ضخامت كوتيكول تحتانى (LCT)، (LCT)، طول سلول إيدرم تحتانى

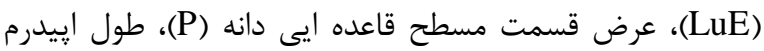

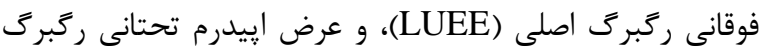

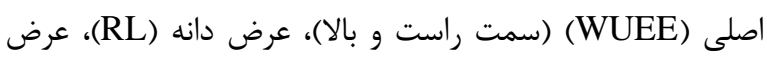

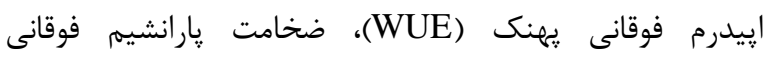

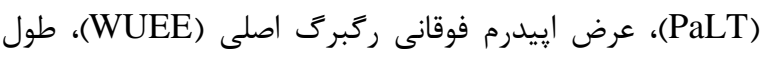

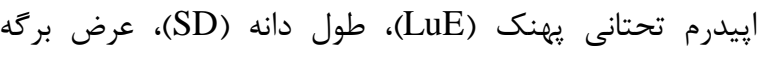

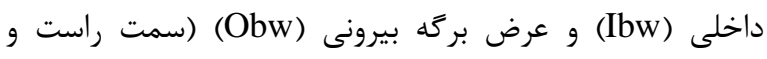

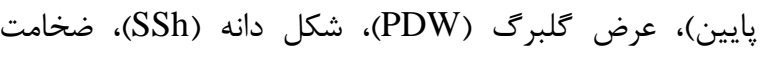

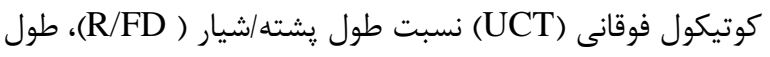

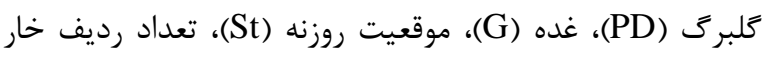

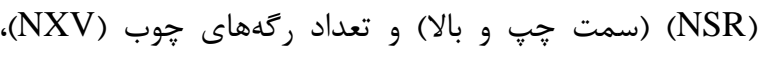

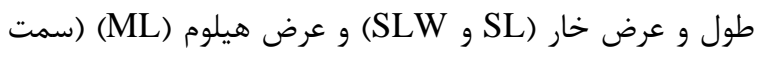

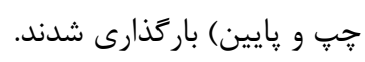

بحث مطالعه ساختار تشريحى برى در كَياهان تيره گلسرخيان و سردهاى مختلف آن يِيوسته مورد توجه محققان قرار داشته دئه

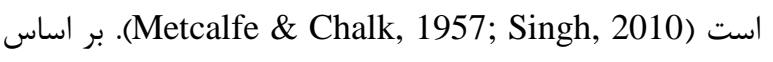
نتايج اين تحقيق نوع كرى يوششى، موقعيت قرار كرفتن روزنه

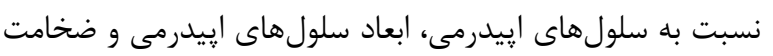

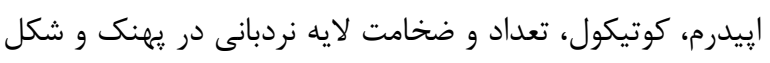

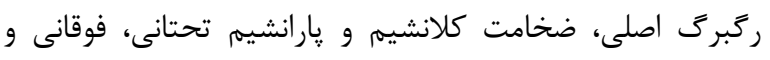

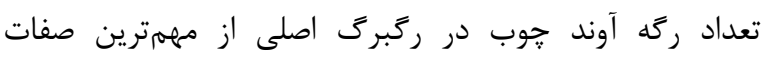

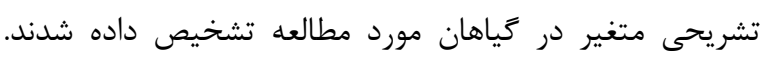

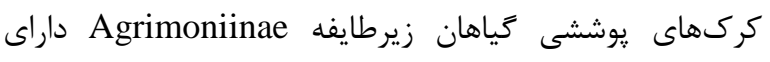
صفات شاخص تيره كلسرخيان (تك سلولى، نوك باريك و بدنه

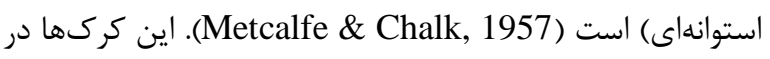
دو سرده Agrimonia Aremonia مشابه، اما در زيركونهها متفاوت

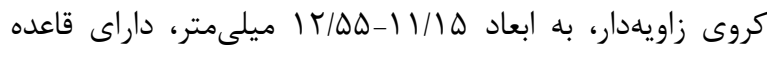

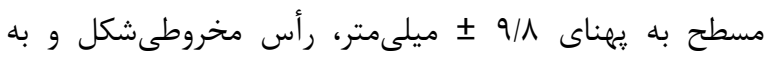

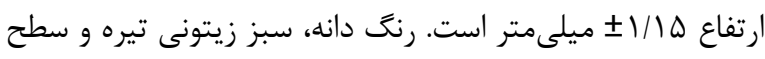

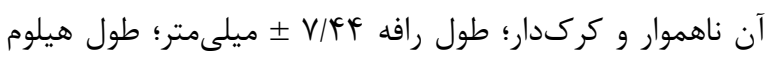

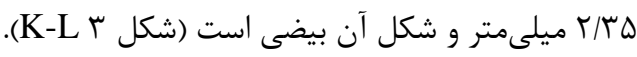
آناليز مولفه هاى اصلى (PCA)

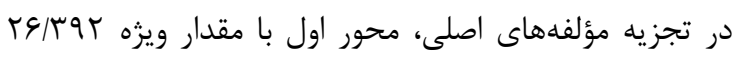

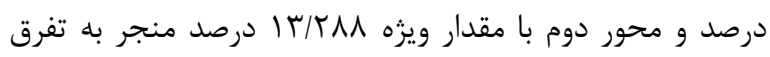

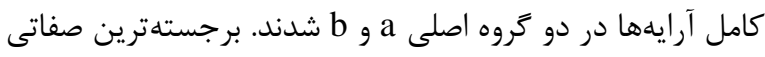

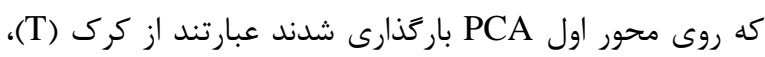

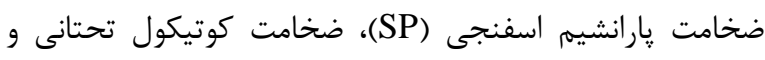

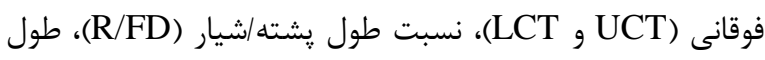

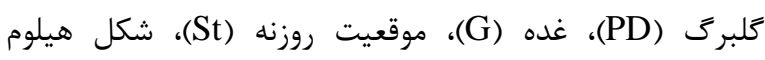

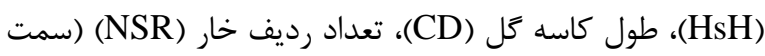

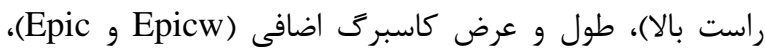

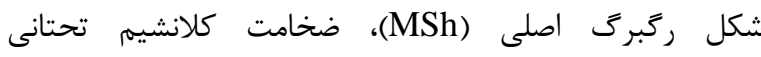

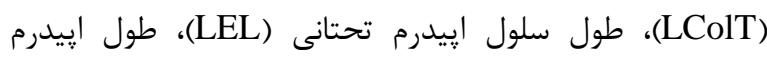

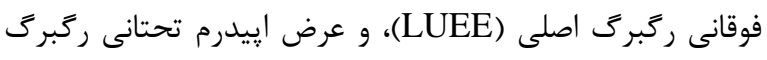

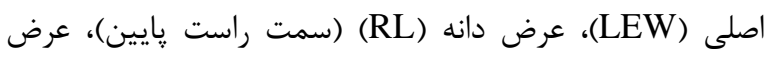

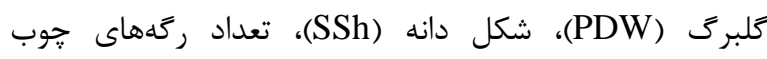

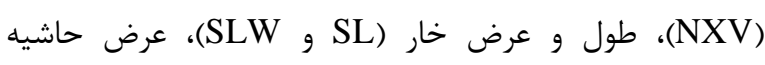

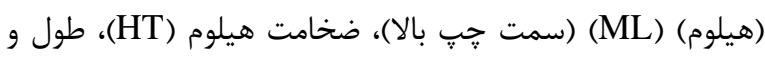

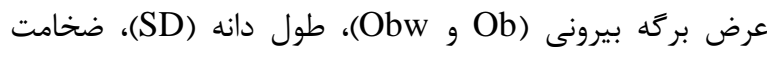

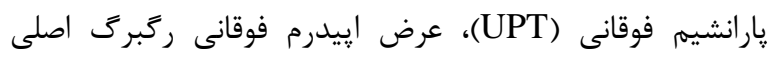
فئ)، (WUEE)

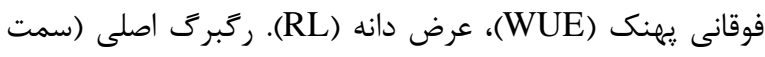

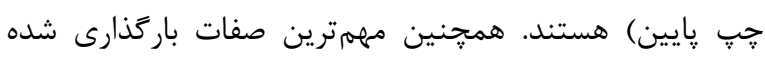

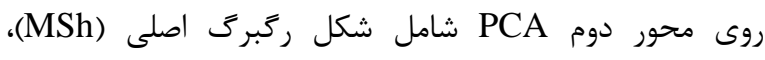

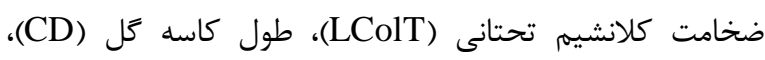



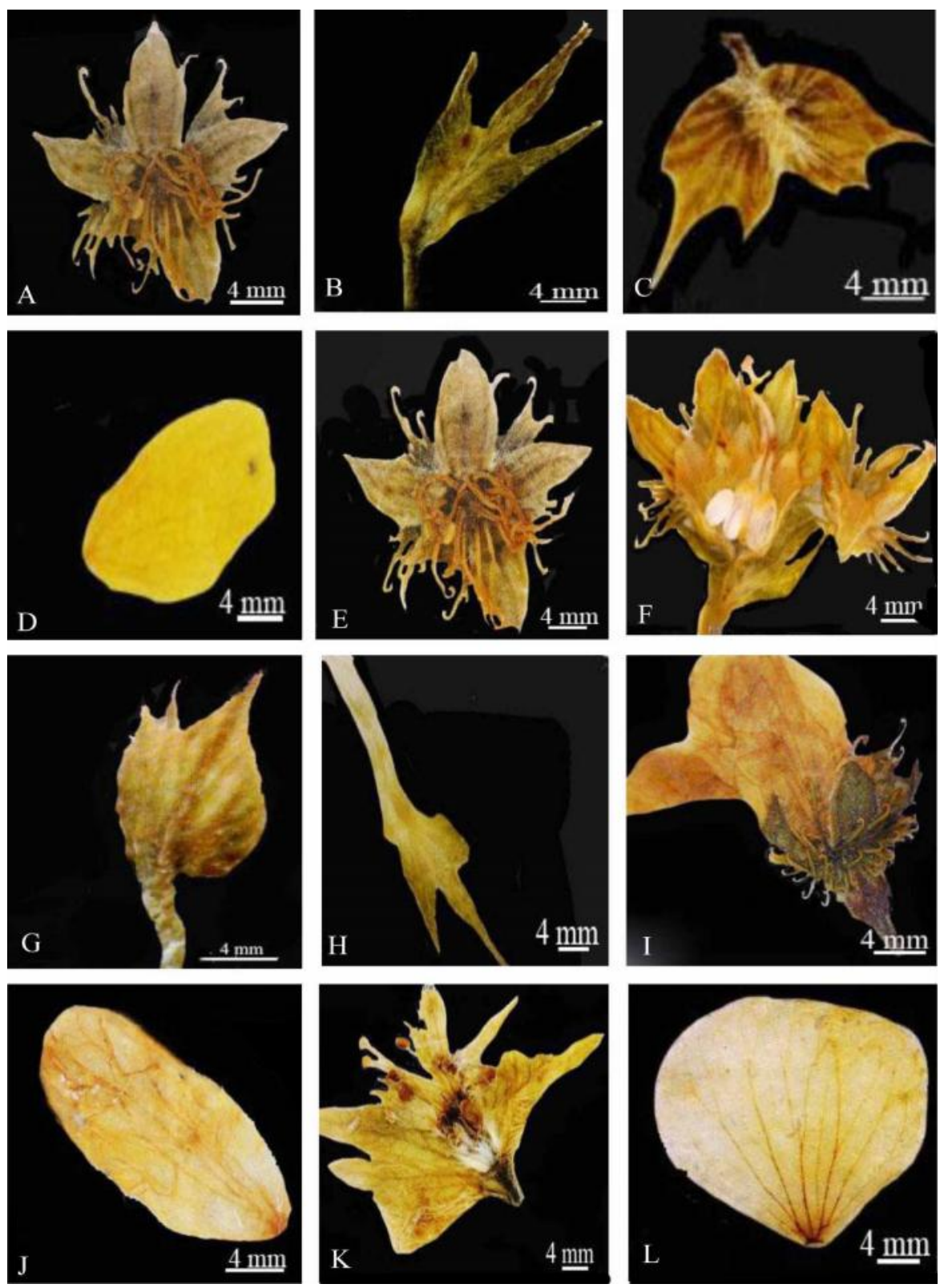

A. eupatoria subsp. .D-G . Agrimonia eupatoria subsp. eupatoria . A-C .Agrimoniinae شكل r- ريختشناسى كل در زيرطايفه Aremonia agrimonioides $\mathbf{J}$-L .A. eupatoria subsp. asiatica $\mathbf{H}-\mathbf{I}$. grandis

Fig. 2. Flower morphology in subtribe Agrimoniinae. A-C. Agrimonia eupatoria subsp. eupatoria. D-G A. eupatoria subsp. grandis. H-I. A. eupatoria subsp. asiatica. J, K. Aremonia agrimonioides.

$$
\text { جدول F- صفات ريختشناسى ميوه در كونهاى مورد مطالعه }
$$

Table 4. Fruit morphological characters in the species studied

\begin{tabular}{|c|c|c|c|c|c|c|}
\hline \multirow[b]{2}{*}{ Species/Subspecies } & \multicolumn{5}{|c|}{ Characters } & \multirow[b]{2}{*}{$\begin{array}{c}\text { R/FD } \\
\mathbf{m m}\end{array}$} \\
\hline & Hsh & $\begin{array}{l}\text { Hd } \\
\text { mm }\end{array}$ & NSR & $\begin{array}{c}\text { Sd } \\
\text { Lr/ Ur }\end{array}$ & $\begin{array}{c}\text { SL } \\
\mathbf{L r} / \mathbf{U r}\end{array}$ & \\
\hline $\begin{array}{l}\text { I. Subtribe Agrimoniinae } \\
\text { 1.Agrimonia eupatoria subsp. eupatoria }\end{array}$ & $\mathrm{Ca}$ & $14.4 * 17.6$ & $3-4$ & Ho-EP/E & $4.8-5.2 / 8-10.8$ & $1.8-3.2 / * 12.8-8.8$ \\
\hline 1.1. A. eupatoria subsp. grandis & $\mathrm{Co}-\mathrm{Ca}$ & $18.8 * 20.8$ & $3-4$ & $\mathrm{P} / \mathrm{E}$ & $4.4-4.9 / 11.4-13.8$ & $2.6-2.4 * 16.4$ \\
\hline 1.2 A. eupatoria subsp. asiatica & $\mathrm{Ca}$ & $12.4 * 14.6$ & 3 & R-EP/E & $4.4-4.2 / 11.16$ & $1.87-3.81 * 14.3-10.8$ \\
\hline $\begin{array}{l}1.3 \text { Aremonia } \\
\text { A. agrimonioides (L.) DC. }\end{array}$ & $\mathrm{Cy}-\mathrm{Ob}$ & $\begin{array}{r}17.2 * 25.4 \\
\mathrm{Cl}: 4.8-8.8\end{array}$ & - & - & - & $2.8-4.6 * 9.2-11.3$ \\
\hline
\end{tabular}


جدوله- صفات ريختشناسى دانه در كونههاى مورد مطالعه.

Table 5. Seed morphological characters in the species studied

\begin{tabular}{|c|c|c|c|c|}
\hline \multirow{2}{*}{ Characters } & \multicolumn{4}{|c|}{ Species } \\
\hline & A. eupatoria subsp. eupatoria & A. eupatoria subsp. grandis & A. eupatoria subsp. asiatica & A. agrimonoides \\
\hline SSh & S-FB & S-FB & $\mathrm{O}-\mathrm{FB}$ & S-FB \\
\hline HT & 3.84 & 2.37 & 2.83 & 0.78 \\
\hline HL & 5.12 & \pm 4.32 & \pm 5.5 & 2.35 \\
\hline ML & 11.81 & 8.68 & 9.98 & - \\
\hline HS & L-Sm & L-Sm & L-Wm & $\mathrm{R}-\mathrm{E} /-\mathrm{Sm}$ \\
\hline $\mathbf{R L}$ & \pm 9.79 & \pm 7.02 & - & \pm 7.44 \\
\hline HL & \pm 6.12 & \pm 5.02 & \pm 1.23 & \pm 9.8 \\
\hline $\mathbf{A}$ & \pm 1.65 & \pm 1.62 & \pm 0.7 & \pm 1.15 \\
\hline SD & $27.75 * 13.06$ & $12.14 * 17.38$ & $13.04 * 12.08$ & $11.15-* 12.55$ \\
\hline SC & LB-DB & Y-LB & B & G \\
\hline \multicolumn{5}{|c|}{$\begin{array}{l}\text { Abbreviations: SSh Seed shape; O-FB ovate- with flat basal part; S-FB spherical-angular with flat basal part; HT Thickness and length } \\
\text { of hilum; HL Hilum length; ML Margin length; HS Hilum shape;L-Sm linear with broad veined margin; L-Wm Linear with broad } \\
\text { margin; R-E/-Sm Round-elliptical/margin without vein; RI Raphe length; HL width of the flat basal part; A, Height of conical end; SD } \\
\text { Seed dimension; SC Seed color; B-DB Light brown-dark brown; Y-LB Yellow-Light brown; G green; }\end{array}$} \\
\hline
\end{tabular}

(P'yankov \& Kondrachuk, 2003). بيشترين وسعت لايه نردبانى (كمترين وسعت لايه اسفنجى) (شكل I G) مربوط به زيركونه A. eupatoria subsp. Eupatoria متعلق به جمعيتى در استان آذربايجان غربى و كمترين لايه نردبانى (بيشترين وسعت

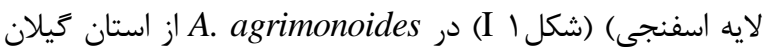
مشاهده شد. در بررسى ساختار تشريحى رگبرگ اصلى، شكل رَبرَ اصلى (Agrimonia شيز تفاوت مشاهده شد. اين صفت مىتواند در جداسازى دو سرده مفيد واقع شود. علاوه بر اين، ضخامت كلانشيم، يارانشيم (تحتانى و فوقانى) و و تعداد ركههاى جوب هم در بين آرايههاى تحت بررسى متغير بودند. اما

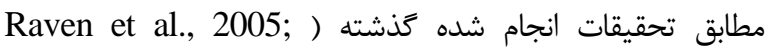
(Metcalfe \& Chalk, 1957 اين صفات تحت تاثير سن كياه و شرايط محيطى قرار دارند و براى رده بندى كارامد نيستند. بر اساس نتايج اين تحقيق، صفات ريختشناسى كل، شكل كلبرى درى (واز تخممرغى تا بيضىشكل در Agrimonia و واز قلبىشكل در Aremonia Agrimonia Aremonia

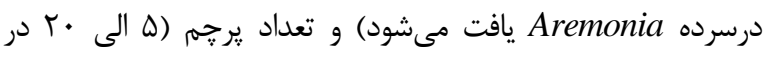
Agrimonia

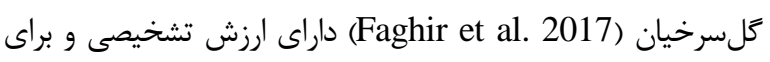
تفكيك دو سرده كارامد هستند. در مطالعات انجام شده قبلى، از ميان صفات ريختشناسى كل، بيشتر بر نقش كليدى صفاتى مانند تعداد

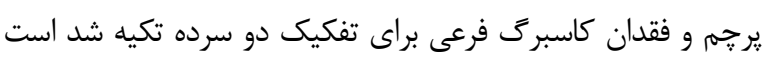

(Tutin et al., 1969; Schönebek-Temesy, 1969) نتايج مطالعه صفات مختلف ريختشناسى ميوه نشان داد كه

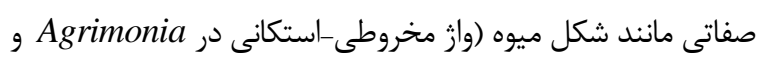

A. eupatoria A. eupatoria subsp. eupatoria,د) A. eupatoria subsp. asiatica راست؛ در subsp. asiatica راست و موجدار ظاهر شدند. اين صفت داراى اهميت تشخيصى

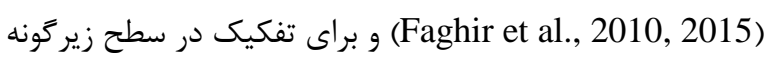
مناسب است. موقعيت قرار زرفتن روزنه نسبت به براى سلولهاى إيدرمى سطوح تحتانى/فوقانى در بين دو سرده Aremonia (همسطح/همسطح) و Agrimonia (برجسته/فرورفته) و نيز بين دين دين

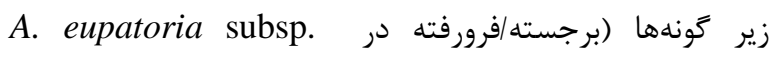
A. eupatoria subsp. و و برجسته/برجسته eupatoria (asiatica

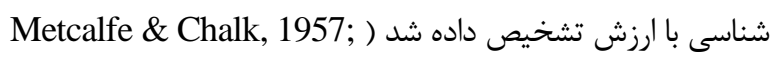
(Faghir et al., 2011 فرو گونهايى استفاده شود. يافتههاى مطالعه تشريحى بيانكر تنوع ابعاد سلولهاى إيدرمى، ضخامت إيدرم و كوتيكول در بين آرايههاى تحت بررسى است. طبق مطالعات انجام شده قبلى اين صفات تحت إيدر تأثير شرايط محيطى و بومشناختى قرار دارند (M Chalk, 1957) A. Metcalfe eupatoria subsp. eupatoria مرطوب رشد مى كند، كمترين ضخامت كوتيكول را دارد. در حالى كه ضخيمترين كوتيكول مربوط به كونه A. agrimonoides است كه درين در

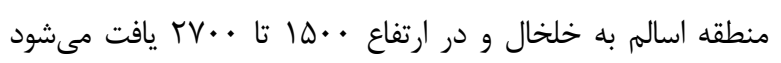
(جدول ()). بر اساس تحقيقات انجام شده قبلى ( Delucia \& (Graemp, 1984 كوتيكول است. وسعت و تعداد لايههاى يارانشيم نردبانى (1 الى ه لايه) و

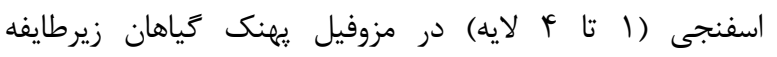
Agrimoniinae اين صفات تابع عواملى نظير دما، خشكى، نور و ارتفاع هستند 

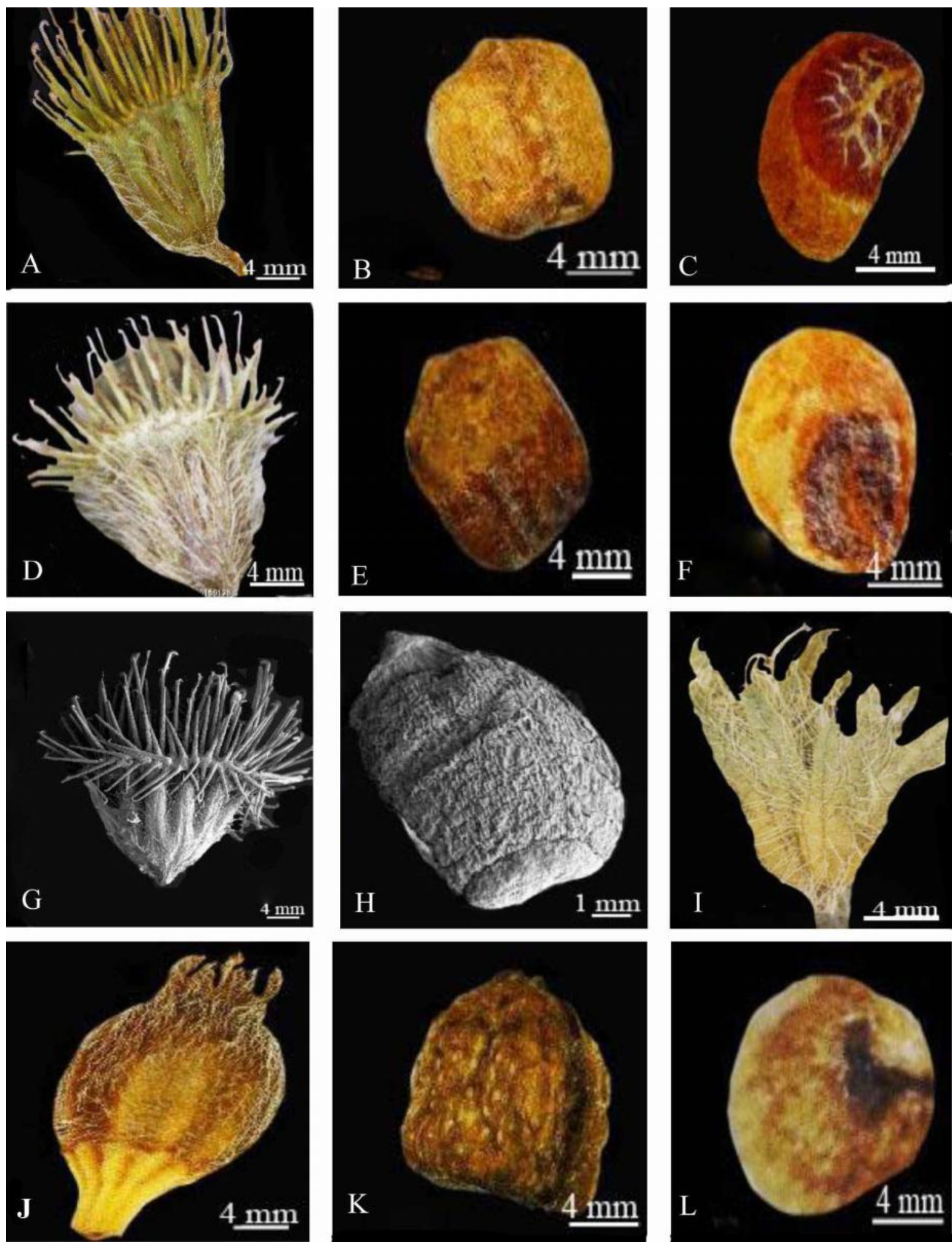

A. eupatoria subsp. .D-F .Agrimonia eupatoria subsp. eupatoria .A-C .Agrimoniinae. شكل r - ميوه و دانه در زيرطايفه Aremonia agrimonioides .I-l A. eupatoria subsp. asiatica .J-H grandis

Fig. 3. Fruits and seed in subtribe Agrimoniinae. A-C. Agrimonia eupatoria subsp. eupatoria. D-F. A. eupatoria subsp. grandis. G-H. A. eupatoria subsp. asiatica. I-1. Aremonia agrimonioides. 
جدول \&- Pفات مورد استفاده در آناليز PCA

Table 6. Character used in PCA analysis.

\begin{tabular}{|c|c|c|c|}
\hline Abbreviation & Character & Abbreviation & Character \\
\hline 1. UCT. & Upper cuticle thickness of blade & $\begin{array}{l}30 . \\
\text { L }\end{array}$ & Number of bract \\
\hline 2. LCT & Lower cuticle thickness of blade & 31. $\mathrm{Ob}$ & Outer bract length \\
\hline 3. LUE & Length of upper epidermis of blade & $\begin{array}{l}\text { 32. } \mathrm{Ob} \\
\mathrm{w}\end{array}$ & Outer bract width \\
\hline $\begin{array}{l}\text { 4. WU } \\
\text { E }\end{array}$ & Width of the upper epidermis of blade & 33. Ib & Inner bract length \\
\hline 5. $\mathrm{LuE}$ & Length of the lower epidermis of blade & 34. Ibw & Inner bract width \\
\hline 6. LET & Width of the lower epidermis of blade & 35. $\mathrm{CD}$ & Calyx length \\
\hline 7. PalT & Palisade parenchymal thickness & $\begin{array}{l}\text { 36. CD } \\
\text { W }\end{array}$ & Calyx width \\
\hline 8. SP & Spongy parenchyma & $\begin{array}{l}\text { 37. Epi } \\
\text { L }\end{array}$ & Epicalyx length \\
\hline 9. LEL & Length of the lower epidermis of midrib & $\begin{array}{l}\text { 38. Epi } \\
\mathrm{w}\end{array}$ & Epicalyx width \\
\hline 10. LEW & Width of the lower epidermis of midrib & 39. Csh & Calyx shape, ovate: 0 , eliptical: 1 \\
\hline $\begin{array}{l}\text { 11. LUE } \\
\mathrm{E}\end{array}$ & Length of the upper epidermis of midrib & 40. Psh & Petal shape: Oval -elliptical :0, obcordate: 1 \\
\hline $\begin{array}{l}\text { 12. WU } \\
\text { EE }\end{array}$ & Width of the upper epidermis of midrib & 41. Hsh & $\begin{array}{l}\text { Hypanthium shape: cup shape: } 0 \text {, cup shape- } \\
\text { rounded:1, obovate-cylindrical: } 2\end{array}$ \\
\hline $\begin{array}{l}\text { 13. UCol } \\
\mathrm{T}\end{array}$ & Upper collenchyma thickness & 42. Hd & Hypanthium length \\
\hline $\begin{array}{l}\text { 14. LCol } \\
\mathrm{T}\end{array}$ & Lower collenchyma thickness & $\begin{array}{l}\text { 43. Hd } \\
\text { w }\end{array}$ & Hypanthium width \\
\hline 15. UPT & Upper parenchymal thickness & $\begin{array}{l}\text { 44. NS } \\
\mathrm{R}\end{array}$ & Number of spine rows: $3-4: 0,3: 1$, spine absent: 2 , \\
\hline 16. LPT & Lower parenchymal thickness & $\begin{array}{l}\text { 45. } \mathrm{R} / \mathrm{F} \\
\mathrm{D}\end{array}$ & Farrow / ridged Length ratio \\
\hline $\begin{array}{l}\text { 17. Mid } \\
\text { W }\end{array}$ & Width of midrib & $\begin{array}{l}\text { 46. R/F } \\
\text { DW }\end{array}$ & Farrow / ridged width ratio \\
\hline $\begin{array}{l}\text { 18. Mid } \\
\text { L }\end{array}$ & Length of midrib & 47. SSh & Seed shape: angular-spherical:0, ovate: 1 \\
\hline 19. $\mathrm{ST}$ & Stomata shape: sunken:0, raised:1, oblate: 2 & 48. SL & Spine length \\
\hline 20. $\mathrm{G}$ & $\begin{array}{l}\text { Glandular trichrome: absent:0, cylindrical- } \\
\text { circular head: } 1\end{array}$ & $\begin{array}{l}\text { 49. SL } \\
\text { W }\end{array}$ & Spine width \\
\hline 21. $\mathrm{C}$ & $\begin{array}{l}\text { Crystal type: polygonal: } 0 \text {, cubic- } \\
\text { polygonal:1without crystal: } 2\end{array}$ & 50. A & Height of the pyramid shape part of the apex \\
\hline 22. MSh & $\begin{array}{l}\text { The shape of the midrib, U shape:0, almost } \\
\text { triangular: } 1\end{array}$ & 51. $\mathrm{P}$ & Width of the flat basal part \\
\hline 23. NXV & Number of xylem strain & 52. $\mathrm{SC}$ & $\begin{array}{l}\text { Seed color: light brown-dark, brown: } 0 \text {, } \\
\text { yellow - light brown: } 1 \text {, light brown: } 2 \text {, green:3 }\end{array}$ \\
\hline 24. $\mathrm{T}$ & $\begin{array}{l}\text { The presence of absence of hairs: } \\
\text { absent:0, present: } 1\end{array}$ & 53. RL & Seed width \\
\hline 25. $\mathrm{PD}$ & Petal length & 54. HL & Seed length \\
\hline 26. Pdw & Petal width & 55. $\mathrm{HsH}$ & Hilum shape \\
\hline 27. SD & Seed dimension & 56. HT & Hilum thickness \\
\hline 28. $\mathrm{Sd}$ & Spine direction & 57. $\mathrm{ML}$ & Width of hilum margin \\
\hline 29. $\mathrm{StN}$ & Number of stamen 5-10: $0,10-20: 1$ & & \\
\hline
\end{tabular}

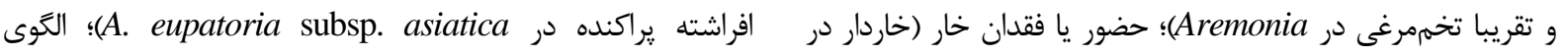
A. eupatoria subsp. eupatoria (Arimonia

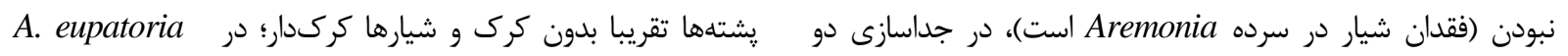

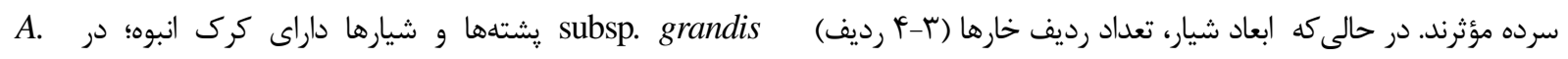

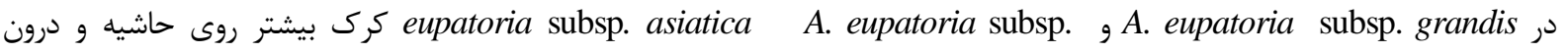

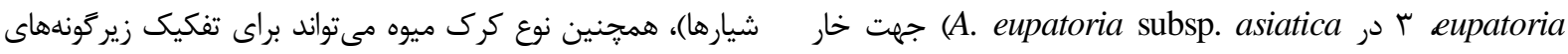

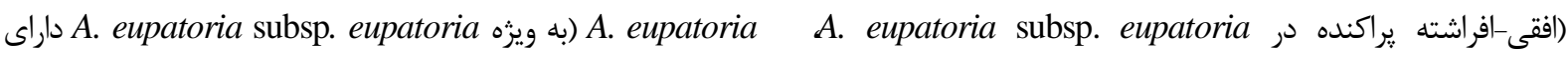
يراكنده و افراشته در A. eupatoria subsp. grandis و بركشته- كركهاى خاكسترى بلند و A. A. eupatoria subsp. asiatica 

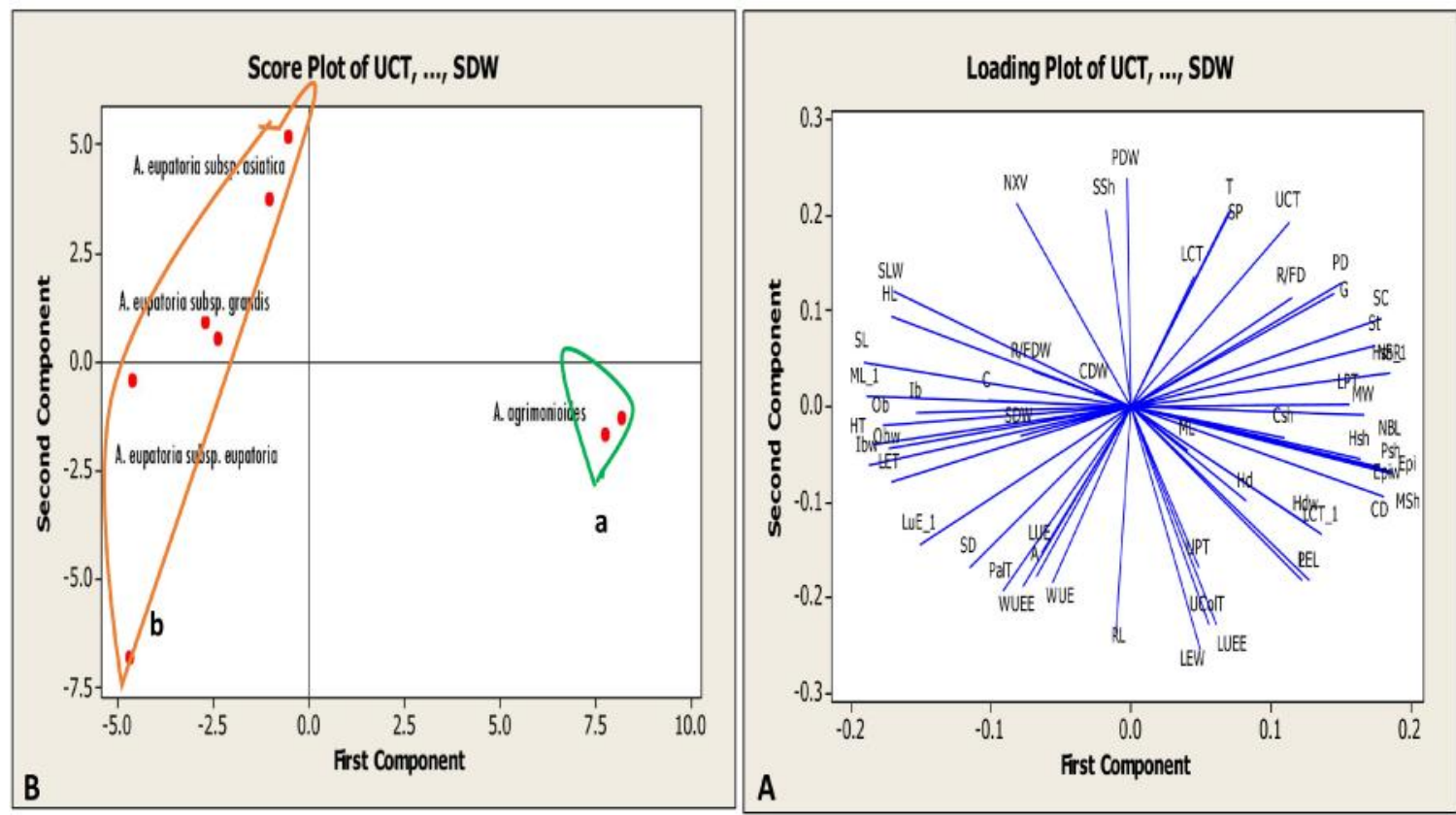

$$
\begin{aligned}
& \text { شكل F - نمودار رسته بندى مولفههاى اصلى صفات تشريحى، ريختشناسى كل، ميوه و دانه آرايهاى تحت مطالعه. ACA .A. باركذارى صفات. } \\
& \text { B }
\end{aligned}
$$

Fig. 4. Ordination diagram of principal component analysis of flower, fruit and seed anatomical and morphological characters of the species studied A. characters loading. B. Species loading.

غذايى بسيار فعال است و در اطراف آن تعداد زيادى ركه آوندى مشاهده مىشود (Thorn, 1981). دانه در سرده Agrimonia)

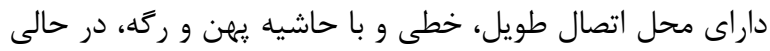
كه در Aremonia كوتاه، تقريبا بيضى شكل، دارئ داراى حاشيه

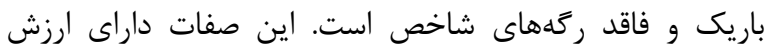
تشخيصى و آرايهشناختى هستند و به عنوان ابزار تشخيصى در

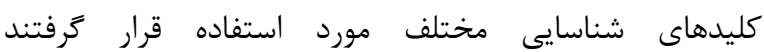
(Brouwer \& Stahlin, 1980). طول رافه دانه در دو سرده Agrimonia و Aremonia تقريبا • ^1 الى • و درصد طول دانه است. اين صفت در بين آرايههاى مورد ارزيابى فاقد اهميت آرايهشناختى است. آناليز عددى گياهان تحت بررسى منجر به تفكيك كامل دو سرده

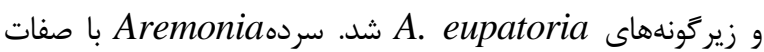
شاخصى از جمله شكل هيلوم (Hsh)، موقعيت روزنه (St)، تعداد رديف خار (NSR)، طول و عرض كاسبرگ اضافى (Epicw و

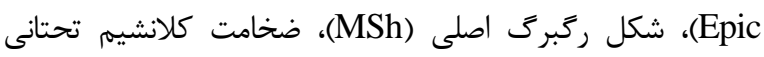
(LCT)، طول سلول إِيدرم تحتانى (LEL)، طول إِيدرم فوقانى

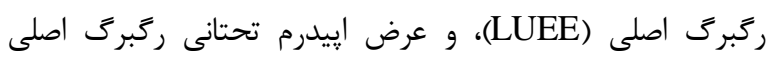
(LEW)، از سرده Agrimonia تفكيك شد. از ميان جمعيتهاى (Lلفي
كرك انبوه و تومنتوز) مورد استفاده قرار گيرد. يافتههاى اين تحقيق از

A. نتايج مطالعات انجام شده كذشته مبنى بر تفكيك زيرگ گونههاى Romero Martin1998; ) حمايت مى عنديند eupatoria Attar et (Schönebek-Temesy 1969 (al., 2007; Johnson et al., 2004 مختلف (Esau, 1977; Barthlott, 1981, 1998) و زيرتيره (Dowidar 2003; Tantawy \& Naseri; 2003) Rosoideae كاربرد داشته است. نتايج صفات ريختشناسى دانه زيرطايفه Agrimoniinea A. eupatoria برسى كروى-زاويهدار با قاعده مسطح است. به غير از subsp. asiatica

$$
\text { ارزش آرايهشناختى اين صفت به سطح زير گونه محدود مىشود. }
$$
يهناى قاعدهاى دانه Aremonia بيشتر از Agrimonia و سطح دانه آن ناهموار و كركدار است، درحالى كه سطح دانه در سرده Agrimonia صاف و بدون كرك است. بر اساس نتايج اين تحقيق، اين صفات در شناسايى دو سرده كارامد هستند. اطلاعات سطح دانه اين بررسى با تحقيقات قبلى ( Chung et (al., 2012 در مطالعه حاضر صفات مرتبط به هيلوم يا محل اتصال دانه به تخمدان مورد ارزيابى قرار گرفت. اين ناحيه در هدايت آب و مر مواد 


\section{RFERENCES}

Abdel Khalik, K.N. 2006. Seed morphology of Cuscuta L. (Convolvulaceae) in Egypt and itssystematic significance. Feddes Repert. 117: 217-224.

Attar, F., Keshvari, A., Ghahreman, A., Zarre, S. \& Aghabeigi, F. 2007. Micromorpholoical studies on Verbascum (Scrophulariaceae) Iran with emphasis on seed surface, capsule ornamentation and trichomes. Flora 202: 169-175.

Barthlott, W. 1981. Epidermal and seed surface characters of plants: systematic applicability and some evolutionary aspects. Nord. J. Bot. 1: 345-354.

Barthlott, W., Neinhuis, C., Cutler, D., Ditsch, F., Meusel, I., Theisen, I. \& Wilhelmi, H. 1998. Classification and terminology of plant epicuticular waxes. Bot. J. Linn. Soc. 126: 237-260.

Brouwen, W. \& Stahlin, A. 1980. Seeds hand book for agriculture, horticulture and forestry with a key for identification identification of the important agricultural seeds; translated for the U.S. Department of Agriculture and the National Science Foundation, Washington D.C, by the Al-Ahram Center for Scientific Translations. pp: 116

Cronquist, A. 1968. The evolution and classification of flowering plants. Nelson, London. pp: 235

Delucia, E. \& Berlyni, G.B. 1984. The effect of increasing elevation on leaf cuticle thickness and cuticular transpiration in balsam fir. Can. J. Bot. 62: 2423-2431.

Chung, K.S., Hoang, N.G., Elisens, W.A. \& Unoh, B.Y. 2012. Phylogenetic implication of seed coat sculpturing in subtribe Agrimoniinae (Rosaceae). Korean J. Pl. Taxon. 42: 247-252.

Esau, K. 1977. Anatomy of seed plants, second ed. Wiley, New York. pp: 767

Faghir, M.B., Attar, F., Farazmand, A., Ertter, B. \& Eriksen, B. 2010. Leaf trichome types in Potentilla L. (Rosaceae) and related genera in Iran. Acta Soc. Bot. Pol. 79: 139-145.

Faghir, M.B., Khairkhah Chaichi, K. \& Shahi Shavvon, R. 2015. Petiole indumentum types of the genus Alchemilla L. (Rosaceae) from Iran. Taxon. Biosys. 2: 23-31.

Faghir, M.B., Ahmadi Gorji, A. \& Heydari, M. 2017 Diversity in floral morphological characters of the genus Alchemilla L. (Rosaceae) from Iran and its taxonomic significance. Nova Biol. Reperta 4: 116-127.

Fock, W.O. 1894. Rosaceae. Pp. 1-60 in Die Naturlichen Pflanzenfamilien, ed. A.ngler. Vol. 3, Abteilung 3. Leipzig: Ilhelm Engelmann.

Hebda, R.J., Chinnappa, C.C. \& Smith, B.M. 1988. Pollen morphology of the Rosaceae of Western Canada. Grana 27: 95-113.

Hebda, R.J. \& Chinnappa, C.C. 1990. Studies on the pollen morphology of Rosaceae in Canada. Rev. Palaeobot. Palynol. 64: 103-108.

Hutchinson, J. 1964. The genera of flowering plants, Vol. 1, Dicotyledons. Clarendon Press, Oxford.

Johnson, L.A., Huish, K.H. \& Porter, J.M. 2004. Seedsurface sculpturing and its systematic significancein Gilia (Polemoniaceae) and segregated genera. Int. J. Plant Sci. 165: 153-172.

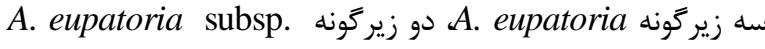
A. eupatoria ; A. eupatoria subsp. asiatica, grandis subsp. eupatoria

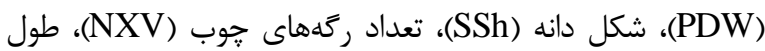

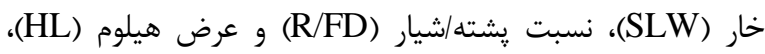
عرض حاشيه هيلوم (ML)، ضخامت هيلوم (HT)، طول بركه بيرونى (Ob) از A (O) eupatoria subsp. eupatoria جدا شدند. از طرفى اين دو زيرگونه هم از طريق صفاتى مانند عرض گلبرى

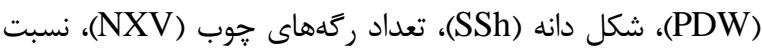

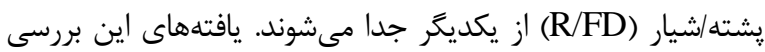
نشان داد علاوه بر صفات ريختشناسى متداولى (به ويزه حضور و

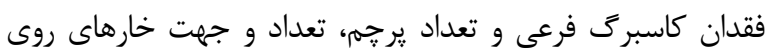
ميوه) كه در رده بندىهاى رايج مورد استفاده قرار مى Romero Martin, 1998; Schönebek-Temesy, تشريحى برى و ساير صفات ريختشناسى گل (شكل گلبرگها، بركهها و گريبان)، ميوه و دانه هم در شناسايى و تعيين حد و مرز

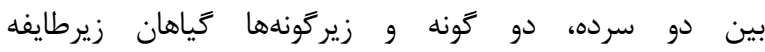
Agrimoniinea

$$
\begin{aligned}
& \text { نتيجه تَيرى } \\
& \text { يافتههاى اين تحقيق نشان داد كه صفات تشريحى و }
\end{aligned}
$$

\section{سياسگز ارى}

بدينوسيله از خانم دكتر فريده عطار مدير هرباريوم مركزى

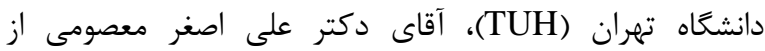
مؤسسه تحقيقات جنگل ها و مراتع كشور (TARI) و دانشكده داروسازى دانشگاه علوم يزشكى تهران (THE)، براى همكارى و و هواتع در اختيار قرار دادن نمونههاى گياهى قدردانى مىنماييه. 
Juzepczuk, S.W. 1941. Rosaceae-Rosoideae, Prunoideae. In: Flora U.S.S.R., Vol. X.: Komarov, V.L. (ed.). Izd. Akad. Nauk. S.S.S.R., Moskva, Leningrad.

Kaliyeva, A.N., Dyuskalieva, G.U., Newsome, A., Zhexembiyev, R.K. \& Kurmanbayeva, M.S. 2014. Studying the polymorphism of different Agrimonia L. populationsgrowing in the south-eastern Kazakhstan. Life Sci. J. 11: 690-692.

Kerr M.S. 2004. A phylogenetic and biogeographic analysis of Sanguisorbeae (Rosaceae), with emphasis on the Pleistocene radiation of the high Andean genus Polylepis. Ph.D. dissertation, University of Maryland, College Park.

Kalkman, C. 2004. Rosaceae. In: Kubitzki, K. (ed.). The families and genera of vascular plants, flowering plants dicotyledons: Celastrales, Oxalidales, Rosales, Cornales, Ericales. Springer, Berlin. 6: 343-386.

Khatamsaz, M. 1992. Rosaceae. In: Assadi, M. et al. (eds.): Flora of Iran, No. 6: 88-140. RIFR, Tehran.

Kumar, S., Jeelani, SM., Rani, S., Kumari, S. \& Gupta, R. C. 2011. RC Exploration of intraspecific cytomorphological diversity in Agrimonia eupatoria L. (Rosaceae) from. Western Himalayas, India. Cytologia 76: 81-88.

Lee, S., K. Heo, J., Cho, C., Lee, W., Chen \& S.C. Kim. 2011. New insights into pollen morphology and its implications inthe phylogeny of Sanguisorba L. (Rosaceae; Sanguisorbeae). Plant Syst. Evol. 291: 227-242.

Metcalfe, C.R. \& Chalk, L. 1957. Anatomy dicotyledons II. Claredon press, Oxford.

Parveen, A. and Qaiser, M. 2014, Pollen flora of Pakistan Lxxi. (Rosaceae). Pak. J. Bot. 46: 10271037.

Potter, D., Eriksson, T., Evans, R.C., Oh, S., Smedmark, JEE. Morgan, DR., Kerr, M., Robertson, KR., Arsenault, M. \& Dickinson, TA. 2007 Phylogeny and classification of Rosaceae. Plant Syst. Evol. 266: 5-43.

P'yankov, V.I. \& Kondrachuk, A.V. 2003, Basic types of structural changes in the leaf mesophyll during adaptation of Eastern Pamir plants to mountain conditions. Russ. J. Plant Physiol. 50: 28-35.
Raven, P.H., Evert, R.F. \& Eichorn, S.E. 2005. Biology of plants. W.H. Freeman, New York, USA.

Reitsma, T.J. 1966. Pollen morphology of some European Rosaceae. Acta Bot. Neerl. 15: 290307.

Robertson, K.R. 1974. The genera of Rosaceae in the southeastern United States. J. Arnold Arbor. 55: 303 662.

Romero Martin, T. 1998. Agrimonia L. In: Castroviejos S., Lainz M., Lopez Gonzales, G., Montserrat, P., Munz Garmendia, F., Paiva, J., Villar, L. (Eds.), Flora Iberica, Real Jardín Botánico, CSIC, Madrid. 6: 369374.

Schonbech-Temesy, H. 1969. Rosaceae. In: Rechinger, K.H. (ed.): Flora Iranica, vol. 66, pp. 78-114.

Schulze-Menz G.K. 1964. Rosaceae. In: Melchior, H. (ed.) Engler's syllabus der pflanzenfamilien II. $12^{\text {th }}$ ed. Gebru“" der Borntraeger, Berlin, pp. 209-218.

Singh, G. 2010. Plant systematics. Science Publishers Enfield, New Hampshire. 702 pp.

Takhtajan, A. 1997. Diversity and classification of flowering plants. Columbia University Press, New York. Pp. 319-320.

Tantawy, M. \& Naseri, M.N. 2003. A contribution to the achene knowledge of Rosoideae (Rosaceae) LM and SEM. Int. J. Agric. Biol. 5: 105-112.

Thorn, J. 1981. Morphology and ultrastructure of maternal seed tissues of soybean in relation to the import of photosynthate. Plant Physiol. 67: 1016-1025.

Tutin, T.G., Heywood, V.H., Burges, N.A., Moore, D.M., Valentine, D.H., Walters, S.M. \& Webb, D.A. (Eds). 1969. Flora Europaea. Vol. 2. Cambridge University Press. pp. 125-153.

Xiang, Y., Huang, CH., Hu, Y., Wen, J., Li, S., Yi, T., Chen, H., Xiang, J. \& Hong Ma H., 2017. Evolution of Rosaceae fruit types based on nuclear phylogeny in the context of geological times and genome duplication. Mol. Biol. Evol. 34: 262-281.

Zhang, S.D., Jin, J.J., Chen, Si.Y., Chase, M.W., Soltis, D.E., Li, H.T., Yang, J.B., Li, D.Z. \& Yi, T.S. 2017. Diversification of Rosaceae since the late cretaceous based on plastid retaceous based on plastid phylogenomics. New Phytol. 214: 1355-1367.

How to cite this article:

Faghir, M.B., Ghandharizadeh, Z. \& Shamshiri, G. 2020. Comparative anatomical and morphological investigations of the subtribe Agrimoniinae (Rosaceae) in Iran. Nova Biologica Reperta 7: 242-255. (In Persian).

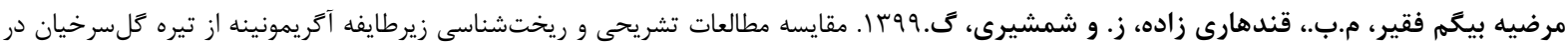

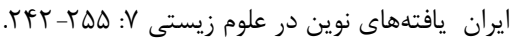

